\title{
A Rawlsian Approach to Distribute Responsibilities in Networks
}

\author{
Neelke Doorn
}

Received: 31 December 2008/Accepted: 19 June 2009/Published online: 23 July 2009

(C) The Author(s) 2009. This article is published with open access at Springerlink.com

\begin{abstract}
Due to their non-hierarchical structure, socio-technical networks are prone to the occurrence of the problem of many hands. In the present paper an approach is introduced in which people's opinions on responsibility are empirically traced. The approach is based on the Rawlsian concept of Wide Reflective Equilibrium (WRE) in which people's considered judgments on a case are reflectively weighed against moral principles and background theories, ideally leading to a state of equilibrium. Application of the method to a hypothetical case with an artificially constructed network showed that it is possible to uncover the relevant data to assess a consensus amongst people in terms of their individual WRE. It appeared that the moral background theories people endorse are not predictive for their actual distribution of responsibilities but that they indicate ways of reasoning and justifying outcomes. Two ways of ascribing responsibilities were discerned, corresponding to two requirements of a desirable responsibility distribution: fairness and completeness. Applying the method triggered learning effects, both with regard to conceptual clarification and moral considerations, and in the sense that it led to some convergence of opinions. It is recommended to apply the method to a real engineering case in order to see whether this approach leads to an overlapping consensus on a responsibility distribution which is justifiable to all and in which no responsibilities are left unfulfilled, therewith trying to contribute to the solution of the problem of many hands.
\end{abstract}

Keywords Responsibility · Problem of many hands ·

Wide Reflective Equilibrium · Procedural ethics · Engineering ethics ·

Socio-technical networks

\footnotetext{
N. Doorn $(\bowtie)$

Department of Technology, Policy and Management, 3TU.Centre for Ethics and Technology, Delft University of Technology, P.O. Box 5015, 2600 GA Delft, The Netherlands e-mail: N.Doorn@tudelft.nl
} 


\section{Introduction}

Technological research is increasingly carried out in networks of organizations with different kinds of actors involved. These networks often lack a strict hierarchy and a clear task division (Achrol 1997; Callon et al. 1992; Hakansson 1989; Halal 1994; Rogers and Bozeman 2001; Saari and Miettinen 2001). Consequently, decisions are subject to negotiation instead of top-down decision making. This increases the likelihood of the problem of many hands, which is the difficulty, even in principle, to identify the person responsible for some outcome (Bovens 1998; Thompson 1980). The occurrence of this problem in R\&D is especially undesirable since technologies can have negative consequences, risks and unforeseen side-effects as well, often with high impact (e.g., the use of asbestos, CFCs, DDT, nuclear waste and the greenhouse effect). These future consequences are often hard, if not impossible, to predict with any accuracy beforehand and they often only materialize during use (Swierstra and Jelsma 2006). Although originally formulated in a backward-looking sense (i.e., in the sense of responsibility for an outcome that has occurred), the problem of many hands manifests itself in a forward-looking sense as well. ${ }^{1}$ The problem then refers to the difficulty of apportioning tasks: which person should see to it that something is brought about or prevented from happening.

In literature, responsibility is often discussed in terms of certain conditions that have to be met before we can ascribe responsibility to someone. Typical conditions are intentionality, voluntariness, knowledge or foreseeability, causality, and blameworthiness (Bovens 1998; Thompson 1980; Corlett 2001; Feinberg 1970; Fischer and Ravizza 1993; May and Hoffman 1991). These conditions are based on the classical notion of individual responsibility. In a collective setting these conditions are difficult to meet. Engineers work in a complex organizational setting, often constrained by market demands, which limits their individual power to act differently. Moreover, since different people contribute it is hard to connect a certain outcome causally to the actions of individual actors (Swierstra and Jelsma 2006). The unforeseeability of future consequences of newly developed technologies complicates these requirements even further. The combination of the collective setting in which technologies are being developed and the unforeseeability of their consequences make it highly unlikely that for every outcome someone can reasonably be held responsible.

One of the reasons for the occurrence of the problem of many hands is the existence of different background theories with respect to the notion of responsibility and, hence, with respect to the allocation of responsibilities (Van de Poel and Zwart, forthcoming). Having different moral background theories, people will have different reasons for ascribing responsibility to someone which ultimately leads to a different allocation of responsibilities. This suggests that, if people are able to reflect on these background theories and principles, learning processes can be triggered which in their turn may contribute to a consensus on the allocation of responsibility (Van de Poel and Zwart, forthcoming).

\footnotetext{
1 See Nihlén Fahlquist (2006) for a detailed elaboration of the difference between forward- and backward-looking conceptions of responsibility.
} 
In the present paper I describe an approach to empirically trace different people's notions of responsibility. The approach is based on the Rawlsian concept of Wide Reflective Equilibrium (WRE). Using Rawls' distinction between different layers of morality I assessed the way people justify their moral opinions (i.e. responsibility ascriptions) and what conditions they endorse for ascribing responsibility. Since the traditional ascription of responsibility is guided by considerations of fairness, I used the Rawlsian concept of WRE to assess the distribution of responsibilities. If a distribution of responsibilities is part of an overlapping consensus it can be considered fair. The main aim of the present paper is to show how the empirical data necessary to assess a person's reflective equilibrium was retrieved. The working hypothesis of this paper is that an interactive method, such as a session in a Group Decision Room (GDR), can trigger learning processes which can ultimately lead to an overlapping consensus on responsibility distributions and ideally also to a more efficacious distribution of responsibilities. The latter is important for addressing issues that are currently overlooked by engineers during design.

The outline of the paper is as follows. Following this introduction I will briefly describe the Rawlsian approaches of WRE and overlapping consensus in section "Rawlsian approaches". In section "GDR session" I will describe how this approach was applied to an artificially constructed network of actors involved in the case of Gilbane Gold, a hypothetical case often used in ethics education for engineering students (see the text box below for a description of the case). Subsequently I will describe the results of the GDR session, followed by a discussion. In the final section conclusions are given, together with recommendations for further research. For reasons of readability the discussion of the different participants' WRE is presented in the appendix of this paper.

\section{Rawlsian Approaches}

The general idea of the present paper is to trace people's opinions on how they would distribute responsibilities in a certain case and to see whether these cohere with the more general moral principles and background theories people endorse. This coherence is important because it can provide a moral basis for distributing the responsibilities. In other words, if a coherence is achieved, the distribution of responsibilities can be rendered fair. We used the Rawlsian concept of Wide Reflective Equilibrium (WRE), initially developed by Rawls (1999 [1971]) and further elaborated by Daniels $(1996,1979)$, as the theoretical framework for retrieving and analyzing these data.

In the concept of WRE a distinction is made between three levels of considerations: (1) considered moral judgments about particular cases or situations, (2) moral principles and (3) descriptive and normative (moral) background theories. Reflective equilibrium refers to a state of coherence between one's considered judgments and moral principles concerning a certain case. According to Rawls, everyday moral reflection takes place by examining our moral judgments on particular matters (level 1) with more general or broader beliefs and principles on 
similar issues (levels 2 and 3). In order to decide how to respond to moral issues people move back and forth between these various beliefs and considerations, reflect on them, revise them if necessary and try to achieve an acceptable coherence. The end-point of this deliberative process is called narrow reflective equilibrium. This narrow reflective equilibrium lacks justificatory power. It does not give a normative answer to the question 'what is right?' but rather describes one's personal moral grammar, which can be typically utilitarian, Kantian or teleological. If we include moral theories and other background theories in the process of critical reflectionand let these also be open to revision-the reflective equilibrium or coherence that is arrived at is called wide (hence, WRE). Contrary to the narrow reflective equilibrium, WRE has justificatory power since it is the result of a searching process of what is right. In the literature the term WRE can refer both the state of coherence between these three layers of morality and to the process or method itself of arriving at such an equilibrium.

Rawls used the concept of WRE in explicating and defending his theory of justice in the context of political philosophy. He tried to develop a criterion of justice that would be fair to all despite the diversity of moral frameworks people endorse. In that sense WRE serves a justificatory purpose. In order to be justified, the outcome of the deliberative process should be fairly achieved, to which end Rawls introduced the so-called 'original position'. In the original position representatives of citizens are placed behind a veil of ignorance, depriving them of information about the individuating characteristics of the citizens they represent, in order to let them reflect upon and after deliberation agree upon principles of justice that would be acceptable to all. Since the people do not know who they represent, people would agree on principles of justice that are fair to all, Rawls argued. As such the fair procedure guarantees the justness of the outcome; hence Rawls' conception of justice as fairness. In his early works Rawls tried to add substantive content to his justice principles, viz. the right to equal basic liberties, the right to fair equality of opportunity and the difference principle (which says that inequalities are allowed only if they work to the benefit of the worst-off group). Recognizing the plurality of incompatible and irreconcilable moral frameworks within a democratic society, Rawls later limited the idea of justice as fairness to a purely procedural conception of justice. People with divergent moral doctrines will most probably not agree on a substantive conception of justice but they can overlap in their acceptance of a procedural conception of justice. For these procedural principles to be justified they must cohere with each individual's background theories and considered judgments. Rawls introduced the term overlapping consensus to refer to these justice principles that are agreed upon by all citizens and that are part of each individual's WRE. It is important to note that this overlapping consensus is not a compromise or modus vivendi. Acceptance of the justice principles must be for the right reasons, i.e. they must cohere with the other convictions, beliefs and theories people hold and be part of each individual's WRE.

Although this short description does not do justice to the richness of Rawls' political theory, the key elements to be remembered for practical application of Rawls' approach are the following: (1) according to Rawls' procedural conception of justice/fairness something can be considered justified if it is the result of a fair 
procedure, e.g. a procedure that is agreed upon by all relevant actors involved ${ }^{2}$; (2) 'being agreed upon' means that it is part of each individual's WRE; (3) WRE refers to a state of coherence between one's considered judgments, moral principles and background theories, none of which is immune for revision in the deliberative process of establishing an equilibrium.

The Rawlsian approach of WRE is particularly interesting because it seems to provide a promising procedure for decision making in situations where people have different moral frameworks, i.e., in situations where it is difficult to arrive at substantive agreement on moral issues. Conceived as a purely procedural theory, the method allows for an objective criterion for decision making. The method does not favor one moral theory over an other. In the deliberative process of getting at an equilibrium, all three layers of beliefs (i.e., the considered judgments, the moral principles and the background theories) are open for revision. Moreover, by focusing on equilibrium people are encouraged to engage in a deliberative process and as such the approach can be considered constructive as well.

\section{GDR Session}

To apply the Rawlsian approach of WRE a group of engineers, researchers and policy makers was invited to reflect on the distribution of tasks and responsibilities in the well-known engineering ethics case of Gilbane Gold (see the text box below for a description of the case). ${ }^{3}$ The participants were invited for a session in the Group Decision Room (GDR), held on September 29, 2008. The GDR is a room with electronic meeting support systems that allow for a participative approach to complex tasks such as (anonymous) discussion, brainstorming, voting et cetera.

\section{Selection of the Participants}

In the Gilbane Gold case some typical roles can be discerned. These are the role of technical expert (David Jackson, Winslow Massin), policy maker (Lloyd Bremen), manager (Frank Seeders, Phil Port, Diane Collins), consultant (Tom Richards) and city water official (anonymous). The participants for the session were selected on the basis of their function and roles in their own professional life. The group of participants consisted of eight professionals in total:

- two technical experts (water treatment and ICT);

- one commercial consultant/manager;

- one representative of a water board, i.e. the body responsible for sewage treatment in the Netherlands;

\footnotetext{
${ }^{2}$ Since Rawls' procedural conception of justice suggests that justice implies fairness the terms fair(ness) and just(ice/ness) will be used interchangeably in the present paper.

3 Some scenes were cut from the movie because we found them biased against certain characters or because they focused too much on the whistle-blowing issue, which was for our purpose less relevant. In total less than four minutes were cut so the main story line was kept intact.
} 
- one representative of the STOWA, the Foundation for Applied Water Research in the Netherlands;

- two experts in the field of public management and policy processes;

- one representative of the Royal Institute of Engineers in the Netherlands (KIVI/ NIRIA), who was involved in the establishment of the professional code for engineers.

By selecting participants with different backgrounds it was attempted to broaden the range of considerations and arguments used in the deliberative process. The participants were not asked to represent a certain role or perspective.

\section{Aim of the Session}

The aim of the GDR session was twofold:

1. to see whether it is possible to uncover the empirical data required to assess an agreement between participants in terms of the individual reflective equilibrium of each participant, i.e. to assess whether the individual participant's distribution of responsibilities coheres with his background theories and considered judgments (methodological objective);

2. to see whether an interactive session, such as a GDR session, triggers learning effects, which may ultimately lead to the construction of an overlapping consensus on an allocation of responsibilities (substantive objective).

Since the case concerned a hypothetical situation, it was not possible to come to a final responsibility distribution to be judged in terms of overlapping consensus. For this, more specialized knowledge on the case was required, for example about the testing and the role of other high-tech companies in the area. In that sense the individual responsibility distributions had an a proviso character. So instead of focusing on overlapping consensus the focus was on the individual WREs of the participants and the extent to which the learning processes, triggered during the GDR session, did contribute to the convergence of opinions.

\section{Approach}

To answer the first question we have to look whether it is possible to uncover the background theories, principles and considered judgments of the participants. The considered judgements were traced during the GDR session itself, both in different voting rounds and in the discussions. The moral background theories were traced by asking the participants to fill in the Ethical Position Questionnaire (EPQ) before the session and to give a written justification of the consensus achieved afterwards. The EPQ is a psychometric scale, developed by Forsyth to measure ethical ideologies (Forsyth 1980; Forsyth et al. 1988). These ideologies indicate the background considerations underlying moral deliberation. Four different ideologies are distinguished in the EPQ along two dimensions. The first dimension refers to the extent to which the respondent rejects universal moral rules in favor of relativism. The 
second dimension refers to the degree to which individuals are idealistic or pragmatic in their attitude toward the consequences of actions. ${ }^{4}$

The EPQ is comprised of 20 statements, 10 representing universalism and 10 representing idealism. Nine-point scales are used to measure the extent to which respondents agree or disagree with each statement. On the basis of the responses to the statements respondents are classified into one of the four ideological categories, as shown in Table 1.

The moral background theories assessed by way of the EPQ provide information on the way of reasoning and of justifying ethical judgments. It is likely that these moral background theories will not change during the GDR session. ${ }^{5}$ However, it is possible that certain judgments, principles and other background theories change. Therefore, the participants were asked to give a written justification afterwards and to reflect on their changed opinions. This reflection would give a first indication to see whether learning had taken place.

\section{Set-up of the Session}

The session consisted of four phases:

1. Introduction to the GDR session and showing of the Gilbane Gold movie and inventory of the relevant actors and responsibilities.

2. Distribution of responsibilities (DoR) by the individual participants amongst different actors.

3. Philosophical intermezzo on responsibility: what conditions need to be fulfilled before one can be held responsible.

4. Discussion on the basis of disagreements and (re-)distribution of responsibilities by the individual participants.

As said above the participants were asked to fill in the EPQ beforehand and to give a written justification afterwards. Figure 1 shows the results of the EPQ in terms of

\footnotetext{
${ }^{4}$ The name of the two dimensions used in the EPQ are somewhat misleading. The term 'relativism', for example, might suggest that participants who scored high on this dimension attributed the responsibilities in a loose way where each shared some of the responsibility. The contrary was the case. It appeared that the participants who scored high on the relativism dimension showed on average a more black-and-white view on responsibility with very distinct responsibility ascriptions. Since the relativists reject universal moral rules, this distinct view must be based on some other source, for example competence, task or function. Particularism, the view that there are no overriding principles applicable in every case but that moral judgments should be based on a case by case basis seems to be a more appropriate name for this dimension [see Dancy (2004) and Hooker and Little (2000) for a defense of this view]. The other extreme of this dimension is then universalism. In the remainder of the text I will use the name universalism to refer to the relativism axis. A similar remark could be made for the idealism dimension. The name idealism might misleadingly suggest that exceptionists and subjectivists are not driven by a vision of how people should behave or how things should be arranged. Although there were no 'subjectivists' in the group of participants, the exceptionist clearly showed that he was motivated by some ideal (in this case, the ideal of efficacy), from which a normative appeal can be derived.

${ }^{5}$ Forsyth does not discuss this explicitly but he compares his own questionnaire with the stages of moral maturity (Kohlberg 1976). He argues that no relation was found between his two dimensions (relativism and idealism) and the stage of moral maturity, implying that the former dimensions are more or less constant in time. In a later paper he suggests that young people's moral philosophy may still be evolving but he did not find evidence for this in his data (Forsyth and Berger 1982).
} 
Table 1 Taxonomy of ethical ideologies

\begin{tabular}{|c|c|c|}
\hline \multirow[t]{2}{*}{ Idealism } & \multicolumn{2}{|l|}{ Universalism } \\
\hline & Low & High \\
\hline \multirow[t]{2}{*}{ High } & Situationist & Absolutists \\
\hline & $\begin{array}{l}\text { Rejects moral rules; advocates individualistic } \\
\text { analysis of each act in each situation; } \\
\text { relativistic }\end{array}$ & $\begin{array}{l}\text { Assumes that the best possible outcome can } \\
\text { always be achieved by following moral } \\
\text { rules }\end{array}$ \\
\hline \multirow[t]{2}{*}{ Low } & Subjectivist & Exceptionist \\
\hline & $\begin{array}{l}\text { Appraisals based on personal values and } \\
\text { perspective rather than universal moral } \\
\text { principles; relativistic }\end{array}$ & $\begin{array}{l}\text { Moral absolutes guide judgments but } \\
\text { pragmatically open to exceptions to these } \\
\text { standards, utilitarian }\end{array}$ \\
\hline
\end{tabular}

Source: Forsyth (1980)

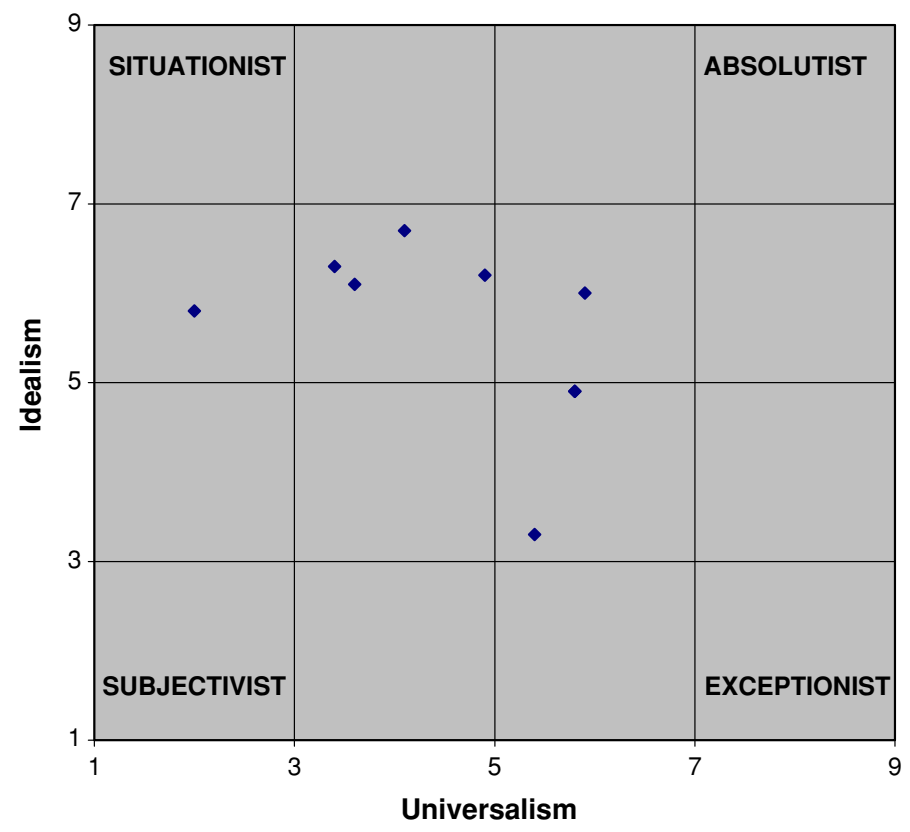

Fig. 1 Ethical positions and EPQ scores of participants

the positions of the different actors along the dimensions universalism and idealism. The mean of all participants was 6.0 on the idealism dimension and 4.9 on the universalism dimension. The graph shows that most participants' ethical position is either 'situationism' or 'exceptionism'. Two participants tend to the 'absolutist' position. None of the participants has a strong tendency towards the position of 'subjectivism'. 


\section{Results}

In this section, the results of the GDR session are described. During the session it was not explicitly aimed to create consensus among the participants. It was rather attempted to trace the opinions of the participants on responsibility and the distribution thereof. In line with the notion of responsibility elaborated by (Goodin 1995), the following definition of responsibility was given before the start of the session: "if $\mathrm{A}$ is responsible for $\mathrm{T}$ then A should see to it that $\mathrm{T}$ is brought about." This definition leaves room for someone else than A carrying out a certain task. Being responsible, in that case, means monitoring or delegating the task. It was also explicitly explained that the kind of responsibility concerned was a forward-looking sense of responsibility ascriptions were related to the bringing about of future events or preventing them from happening. The more blame-oriented backward-looking ascriptions for responsibility were not explicitly taken into account. Moreover, it was also emphasized that the discussion was about moral responsibility, as opposed to legal notions of responsibility, which can go further than a person's professional task description. The discussions were recorded on audiotape.

\section{Results Part 1: Introduction}

As an introduction to the session and the electronic equipment the participants were asked to brainstorm on the relevant actors and responsibilities. For both items a preestablished list was given (marked with an asterisk *). The relevant actors and responsibilities as identified by the participants are shown in Tables 2 and 3 respectively.

Table 2 Relevant actors (actors marked with * were identified before start of brainstorm exercise; other actors followed from brainstorm exercise)

\section{Actors}

David Jackson-Environmental Engineer Z-corp*

Tom Richards-Environmental Engineering Consultant*

Phil Port-Manager Environmental affairs Z-corp*

Frank Seeders-Engineering manager Z-corp*

Diane Collins_-Vice-President and Plant Manager Z-corp*

Lloyd Bremen-former State Commissioner Environmental Protection*

Media (replacing TV reporter Maria Renato)*

Professional organization (replacing Professor Emeritus Dr. Winslow Massin)*

Local water treatment authority* (representatives of) Farmers' Association

National Environmental Protection Agency

(US) State Environmental Protection Agency

Environmental activist group

Competitors of the local industry, who operate under less strict regulation 
Table 3 Relevant responsibilities (responsibilities marked with * were identified before start of brainstorm exercise; other responsibilities followed from brainstorm exercise)
Responsibilities

(improving) Test methods*

(improving) Law (test methods; requirements)*

(monitoring) Waste water*

Determination of toxicity of sludge*

Informing local authorities about flaws in test methods*

Informing press*

Informing farmers*

Monitoring soil quality

Monitoring crops

Developing new technologies for wastewater treatment

Plant production planning

Changing production methods

Good housekeeping in industrial processes

$\mathrm{R} \& \mathrm{D}$ for new environment friendly technologies production technologies by Z-corp

Informing authorities about contamination/concentrations in sludge

Financing the improvement of water treatment

\section{Results Part 2: Distribution of Responsibilities (First Voting Round)}

The participants were asked to fill a two-dimensional matrix; the rows contain the different actors and the columns contain the different responsibilities. They were asked to assign each combination of actor-responsibility a number, indicating the degree of responsibility (ranging from 0 "not responsible at all" to 4 "fully responsible"). Twelve of the combinations with the highest disagreements were selected by the moderators during the session to be elaborated on by the participants. Table 4 shows the result of these 12 combinations of actorresponsibility. The numbers in the columns denote the number of participants who assigned the particular level or responsibility, e.g., for the improvement of the test methods, two participants thought David Jackson was not responsible at all, none of the participants thought that he was barely responsible, one participant thought he was partly responsible, three participants considered him to a large extent responsible and two participants thought David was fully responsible for the improvement of the test methods. This particular example already reveals a substantial disagreement amongst the participants. The last column shows the median of the voting results. ${ }^{6}$

\footnotetext{
${ }^{6}$ Since the voting is done on an ordinal scale, i.e. a scale in which the numbers indicate a rank number, the commonly used statistical measures mean and standard deviation are statistically unsound. In ordinal scales, the adequate measure to indicate the central tendency of the measured variable is the median. The median is described as the middle number of a group of numbers that have been arranged in order by size. In case of an even number, the median is the mean of the two middle numbers. In ordinal scales no separate measure to indicate the statistical dispersion is available.
} 
Table 4 Responsibility ascriptions in first voting round

\begin{tabular}{|c|c|c|c|c|c|c|}
\hline Degree of responsibility ${ }^{a}$ & 0 & 1 & 2 & 3 & 4 & Median \\
\hline \multicolumn{7}{|l|}{ (improving) Test methods } \\
\hline David Jackson & 2 & 0 & 1 & 3 & 2 & 3.0 \\
\hline Phil Port & 4 & 0 & 0 & 2 & 2 & 1.5 \\
\hline Diane Collins & 4 & 1 & 2 & 1 & 0 & 0.5 \\
\hline Tom Richards & 4 & 1 & 1 & 2 & 0 & 0.5 \\
\hline Local water authority & 1 & 1 & 3 & 1 & 2 & 2.0 \\
\hline \multicolumn{7}{|l|}{ Determination of toxicity of sludge } \\
\hline David Jackson & 5 & 1 & 0 & 1 & 1 & 0.0 \\
\hline \multicolumn{7}{|l|}{ Informing local authorities about flaws in test methods } \\
\hline Diane Collins & 2 & 0 & 0 & 2 & 4 & 3.5 \\
\hline Competitors of the local industry, under less strict regulation & 5 & 1 & 0 & 1 & 1 & 0.0 \\
\hline \multicolumn{7}{|l|}{ Informing farmers } \\
\hline Environmental Activist Group & 1 & 2 & 1 & 2 & 2 & 2.5 \\
\hline Media & 5 & 1 & 0 & 2 & 0 & 0.0 \\
\hline \multicolumn{7}{|l|}{ Good housekeeping in industrial processes } \\
\hline David Jackson & 4 & 3 & 0 & 0 & 1 & 0.5 \\
\hline \multicolumn{7}{|c|}{$\mathrm{R} \& \mathrm{D}$ for new environment friendly production of technologies by Z-corp } \\
\hline Tom Richards & 4 & 1 & 0 & 2 & 1 & 3.0 \\
\hline
\end{tabular}

${ }^{a}$ Numbers $0-4$ indicate degree of responsibility: $0=$ not responsible at all; $1=$ barely responsible; $2=$ partly responsible; $3=$ to a large extent responsible; $4=$ fully responsible

\section{Results Part 3: Conditions for Responsibility}

The participants were asked to brainstorm on possible conditions for responsibility. The participants were explicitly asked to give conditions which, taken together, would ideally be sufficient to ascribe responsibility to someone and which, taken separately, would each be necessary as well. This resulted in a list of approximately 30 conditions/remarks. The participants were then given a short explanation of four philosophical notions of responsibility as they are used in scholarly literature, viz. freedom (no coercion, alternatives for action), knowledge (possibility to oversee the consequences of one's actions), influence or causality (the possibility to influence the outcome) and intentionality (the ability to make rational choices and to make act intentionally). After that the list was discussed and a shortlist of eight conditions was established. Accordingly, the participants were asked to individually rank the conditions from most important (1) to least important (8), with the opportunity to leave out some conditions, which they considered not necessary.

The eight conditions identified are the following:

- Freedom: this condition was conceived in a broad sense. The participants argued that freedom is often limited by physical and/or psychological boundaries. They identified a number of potential obstacles for freedom: conflict with other responsibilities, dependency on the openness and honesty of other actors involved. One of the participants argued that one cannot ascribe responsibility to someone if 
that person does not have the opportunity to make mistakes. This 'space for learning' can also be considered a kind of freedom.

- Competence: one cannot ascribe responsibility to someone who is not competent, both in a professional sense as well as mentally. Related to the latter is the requirement that one needs to have the ability to view the world in a moral way, to make sense of responsibility in the first place.

- Knowledge: by knowledge the participants meant that all relevant information is known, including management information, insight in the boundary conditions and other relevant (conflicting) responsibilities. In addition, one needs to know that one's actions matter.

- Opportunity for action: this condition refers to 'internal' drivers or attributes of the person him/herself. The person should have the right/power/possibility for action, should have the mandate for action, knowledge of the efficacy of one's action, absence of group pressure. Under this heading the participants also mentioned the 'moral' right and duty to action, viz. whistle-blowing and civil disobedience.

- Boundary conditions: where the previous condition can be conceived as an 'internal' condition, this condition more or less refers to 'external' conditions. This condition, which is also related to the freedom condition but according to the participant not completely overlapping, is the requirement that boundary conditions are favorable. Examples of these boundary conditions are the financial possibilities, dependencies or contextuality, commitment by higher management, support, trust, resources.

- Task: related to responsibility in a professional setting is the task responsibility. One of the requirements is that there is clarity on the expectations.

- Commitment: this condition was added to denote that one cannot ascribe responsibility to someone if that person is not involved in the project or network under consideration. One of the participants phrased it this way: "One cannot ascribe responsibility to someone if this has no repercussion on the person himself. There should be a link between the action and the outcome. If someone is responsible for something that is completely isolated from everything that influences that person, something is created which is outside the system. Maybe, this is not really a necessary condition but it is just not wise to do it. It wouldn't be credible." 7 Although there was some discussion on how to exactly formulate this criterion most participants agreed that the person should at least be a stakeholder.

- No unfavorable consequences for oneself: during the brainstorm this condition was mentioned as a possible condition. During the discussion most participants rejected this as a necessary condition.

The conditions 'freedom', 'competence', 'knowledge', and 'opportunity for action' more or less resemble the traditional conditions mentioned in philosophical literature (freedom, intentionality, knowledge, and influence or causality). ${ }^{8}$

\footnotetext{
7 Quotation participant Z. Translation by author.

${ }^{8}$ The condition of blameworthiness, i.e. the causally contributory action was in some way faulty in the sense that the actor can be blamed for the contributory action, is sometimes included as well. Since the present paper deals with forward-looking responsibility explicitly, this backward-looking condition of blameworthiness is not included.
} 
Table 5 Ranking responsibility conditions

\begin{tabular}{llllllllllll}
\hline & \multicolumn{3}{c}{ Number of votes in each ranking } & \multicolumn{3}{c}{ Number of votes } \\
\cline { 2 - 8 } Highest to lowest weight ranking & 1 & 2 & 3 & 4 & 5 & 6 & 7 & 8 & & \\
\hline Knowledge & 3 & 1 & 1 & 3 & 0 & 0 & 0 & 0 & 8 & \\
Competence & 2 & 1 & 1 & 0 & 3 & 0 & 1 & 0 & 8 & \\
Freedom & 2 & 0 & 2 & 2 & 1 & 1 & 0 & 0 & 8 & \\
Commitment & 1 & 0 & 0 & 1 & 0 & 1 & 2 & 0 & 5 & \\
Opportunity for action & 0 & 4 & 3 & 1 & 0 & 0 & 0 & 0 & 8 & \\
Boundary conditions & 0 & 1 & 1 & 1 & 1 & 2 & 0 & 0 & 6 \\
Task & 0 & 1 & 0 & 0 & 2 & 2 & 1 & 0 & 6 \\
No negative consequences & 0 & 0 & 0 & 0 & 0 & 0 & 0 & 2 & 2 \\
\hline
\end{tabular}

Although it is acknowledged that the eight conditions are not fully independent, the participants gave all conditions a very specific interpretation. Hence, the ultimate conditions were sufficiently distinct as to keep them all included.

Table 5 shows the aggregated results of the individual rankings, where the numbers in the columns 2-8 indicate how many times that condition had the ranking indicated in the upper row. The last column indicates the number of participants who indicated this condition as a necessary condition for ascribing responsibility. Hence, if a particular condition had eight votes this means that all participants indicated this condition as a necessary condition. It is interesting to see that the four conditions mentioned by all participants are exactly the four 'traditional' conditions 'freedom', 'competence', 'knowledge', and 'opportunity for action'. The criteria 'boundary conditions' and 'task' were mentioned by six out of eight participants, the criterion 'commitment' was mentioned by five out of eight participants, and the criterion 'no negative consequences' by only two out of eight participants.

\section{Results Part 4: (re)Distribution of for Responsibilities (Second Voting Round)}

After the discussion on responsibility conditions the participants were asked to discuss some of the most striking points of disagreement. Subsequently they were asked to (re)distribute the responsibilities. The results of this second voting round are shown in Table 6.

\section{Discussion}

As discussed previously the GDR session served a double purpose. The first aim was to see whether it was possible to assess the different layers of morality, i.e. the considered judgments, moral principles and background theories of the participants. The second aim was to see whether the WRE approach helped to construct a distribution of responsibilities that is agree upon by all and that is both fair and complete. 
Table 6 Responsibility ascriptions in second voting round

\begin{tabular}{lllllll}
\hline Degree of responsibility $^{\mathrm{a}}$ & 0 & 1 & 2 & 3 & 4 & Median \\
\hline
\end{tabular}

(improving) Test methods

David Jackson

Phil Port

Diane Collins

Tom Richards

Local water authority

$\begin{array}{llllll}3 & 2 & 2 & 1 & 0 & 1.0 \\ 1 & 1 & 4 & 1 & 1 & 2.0 \\ 3 & 1 & 0 & 4 & 0 & 2.0 \\ 6 & 1 & 1 & 0 & 0 & 0.0 \\ 2 & 2 & 2 & 1 & 1 & 1.5 \\ & & & & & \\ 7 & 1 & 0 & 0 & 0 & 0.0 \\ & & & & & \\ 0 & 0 & 0 & 3 & 5 & 4.0 \\ 3 & 0 & 1 & 2 & 2 & 2.5 \\ & & & & & \\ 0 & 2 & 3 & 3 & 0 & 2.0 \\ 1 & 3 & 0 & 4 & 0 & 2.0\end{array}$

Determination of toxicity of sludge

David Jackson

Informing local authorities about flaws in test methods

Diane Collins

Competitors of the local industry, under less strict regulation

Informing farmers

Environmental Activist Group

Media

Good housekeeping in industrial processes

David Jackson

$\begin{array}{lllll}1 & 1 & 3 & 3 & 0\end{array}$

$\mathrm{R} \& \mathrm{D}$ for new environment friendly production of technologies by Z-corp

Tom Richards

$\begin{array}{llllll}5 & 2 & 0 & 1 & 0 & 0.0\end{array}$

${ }^{a}$ Numbers $0-4$ indicate degree of responsibility: $0=$ not responsible at all; $1=$ barely responsible; $2=$ partly responsible; $3=$ to a large extent responsible; $4=$ fully responsible

\section{Individual Assessment of the Different Layers of Morality}

To start with the first objective, the responsibility conditions were conceived of as moral principles and the distribution of responsibilities as considered judgments. It was assumed that the ethical position that followed from the EPQ, gives an indication of the third level of Rawls' WRE (moral background theories). ${ }^{9}$ The EPQ was used for this because this questionnaire is explicitly aimed at explaining how people's ethical ideologies or positions, affect their way of reasoning and justifying outcomes. To qualitatively assess the coherence between these layers, the arguments the participants used during the discussion were also closely looked at and compared with the more quantitative voting results of the session. For a detailed discussion of the different participants' WRE the reader is referred to the Appendix at the end of this paper.

The discussion of the different participants' (moral) background theories, moral principles and considered judgments shows that it is possible to trace these three

\footnotetext{
9 Although the ethical positions of the EPQ, being an indication of one's moral background theories, do not cover the whole set of background theories Rawls' labeled as level 3 considerations-these include both moral and other kinds of background theories - other theories, e.g. scientific background theories, were deliberately left out because that would have required more detailed information on the case itself. In fact, Rawls himself is also a bit ambiguous at this point. On the one hand he seems to include also more general background theories in these level 3 considerations, but in the discussion on wide versus narrow reflective equilibrium he focuses on the moral background theories only.
} 
layers of morality. Although some philosophers doubt whether reflective equilibrium is something which could be established from a third-person point of view (Musschenga 2005), the discussion of the data shows that it is possible to give a plausible account of the coherence between the three layers.

In section "Results part 3: conditions for responsibility" it was already mentioned the four conditions that were deemed necessary by all participants were exactly the four conditions that are mentioned in philosophical literature. If we compare these 'traditional' responsibility conditions with those that followed from the participants' brainstorm, it seems that the traditional conditions are less contextspecific. Especially the conditions 'competence' and 'opportunity for action', and to some lesser extent the condition 'freedom' and 'knowledge', were phrased in a rather abstract way, which did not so much focus on a person's position within the external world but more on certain characteristics or abilities of the person him or herself. The remaining four conditions ('boundary conditions', 'commitment', 'task', 'no unfavorable consequences for oneself') on the contrary were more related to the person's position within the world. It is therefore interesting to see that the participants who scored high on the universalism dimension (participants Z, Y and S) gave a higher priority to these more 'abstract conditions' compared to the participants who scored low on the universalism dimension. Competence, e.g., was deemed the most or second most important condition for participants $\mathrm{Z}, \mathrm{Y}$ and $\mathrm{S}$, whereas most participants who scored low on universalism (X, W, and $\mathrm{U}$ ) ranked this condition below typical contextual conditions like 'commitment' or 'boundary conditions'.

The results show that the participants' ethical positions indicate a way of reasoning, rather than that they predict certain judgments. The three different ethical positions - there were no participants who adhered to the position 'subjectivism' all seem to have a guiding question in the deliberation (see the Appendix for details). For the absolutist this question is 'how to make true the ideal world?', typical situationists are guided by the question 'what is (morally) expected in this context?' and for exceptionists this question is 'what is most effective?'. These questions do not predict beforehand how the actual distribution of responsibilities of those particular participants will look like. After all, different participants with a similar ethical position do not necessarily agree on the responsibility distribution beforehand, as can be seen in Table 6 . This table shows the voting results of the situationists only. If we compare Table 4 (results of all participants) with Table 7 (results of situationists only) it can be seen that both tables have a similar spreading. However, although people with similar background theories differ in the actual distribution of responsibilities, the kind of arguments they use and by which they can be convinced show a striking similarity.

If we consider the allocation of responsibilities, there seem to be roughly two ways to approach this. The first is to start with the list of responsibilities and see who should be responsible for that particular issue. This approach seems to start from a requirement of, what we tentatively call completeness. The second is to start with the actors and see what responsibility could be fairly or reasonably ascribed to this particular actor. This approach is more consistent with the scholarly literature on responsibility. Within the group of eight participants only two participants $-Z$ 
Table 7 Responsibility ascriptions in second voting round (situationists only)

\begin{tabular}{|c|c|c|c|c|c|c|}
\hline Degree of responsibility ${ }^{a}$ & 0 & 1 & 2 & 3 & 4 & Median \\
\hline \multicolumn{7}{|l|}{ (improving) Test methods } \\
\hline David Jackson & 3 & 0 & 0 & 1 & 0 & 1.0 \\
\hline Phil Port & 1 & 0 & 2 & 0 & 1 & 2.0 \\
\hline Diane Collins & 3 & 0 & 0 & 1 & 0 & 2.0 \\
\hline Tom Richards & 3 & 1 & 0 & 0 & 0 & 0.0 \\
\hline Local water authority & 1 & 2 & 1 & 0 & 0 & 1.5 \\
\hline \multicolumn{7}{|l|}{ Determination of toxicity of sludge } \\
\hline David Jackson & 4 & 0 & 0 & 0 & 0 & 0.0 \\
\hline \multicolumn{7}{|l|}{ Informing local authorities about flaws in test methods } \\
\hline Diane Collins & 0 & 0 & 0 & 1 & 3 & 4.0 \\
\hline Competitors of the local industry, under less strict regulation & 2 & 0 & 1 & 0 & 1 & 2.5 \\
\hline \multicolumn{7}{|l|}{ Informing farmers } \\
\hline Environmental Activist Group & 0 & 1 & 2 & 1 & 0 & 2.0 \\
\hline Media & 1 & 2 & 0 & 1 & 0 & 2.0 \\
\hline \multicolumn{7}{|l|}{ Good housekeeping in industrial processes } \\
\hline David Jackson & 1 & 0 & 2 & 1 & 0 & 2.0 \\
\hline \multicolumn{7}{|l|}{$\mathrm{R} \& \mathrm{D}$ for new environment friendly production of technologies by Z-corp } \\
\hline Tom Richards & 3 & 1 & 0 & 0 & 0 & 0.0 \\
\hline
\end{tabular}

${ }^{a}$ Numbers $0-4$ indicate degree of responsibility: $0=$ not responsible at all; $1=$ barely responsible; $2=$ partly responsible; $3=$ to a large extent responsible; $4=$ fully responsible

and $\mathrm{X}$-followed the completeness approach. In their discussion they focussed less on the responsibility conditions. Most of the other participants used the conditions to show which actor should can be ascribed what responsibility. Only one participant, W, emphasized both the fairness and the completeness of the responsibility distribution. No systematic difference between the participants emphasizing fairness and those emphasizing completeness could be found. Neither was there any similarity between participant $\mathrm{Z}$ and $\mathrm{X}$ in terms of their ethical position. In fact, they were positioned almost diagonally opposed ( $\mathrm{Z}$ had a low score on idealism and a high score on universalism, whereas and $\mathrm{X}$ had a high score on idealism and a low score on universalism). As such the focus on either fairness or completeness does not seem to be related to one's moral background theory. This result is somewhat surprising. Since people with a similar moral background theory appear to justify outcomes in a similar way, one would expect that they are driven by similar criteria for responsibility ascriptions as well. Further research is needed to substantiate the relationship between moral background theory and criteria for responsibility distributions.

\section{Learning Effects Triggered During the GDR Session}

The second objective of the session was to see whether an interactive session, of which a GDR session is just one example, contributes to the construction of an 
overlapping consensus. Since the session dealt with a hypothetical case it was difficult to discuss something like an end result. In a real engineering or R\&D situation, the GDR session will be one meeting in a whole process of cooperation. The question will then be whether the GDR session will contribute to a division of responsibility which is agreeable by all. In the present example it is not possible to assess these long-term effects. Moreover, detailed knowledge on particular circumstances was lacking. It is therefore not possible to examine whether there is an overlapping consensus. It is possible, however, to see whether the session triggers learning effects necessary for the construction of a Rawlsian consensus. In order to be acceptable by all, people need to learn about each other opinions, be able to look at things from an other perspective, etc. So the leading question is: did the GDR session indeed trigger such learning effects and if so, did these learning effects contribute to convergence in opinions?

To answer this question we must realize that there was a twofold intervention during the GDR session. Not only were the participants asked to interact, they were also informed by philosophical notions on responsibility. It is difficult to separate the effects of the two interventions. To see how the participants changed their opinions it is interesting to take a look at David Jackson's responsibility to improve the test methods. In the first round most participants said that David Jackson was fully or to a large extent responsible (see second row in Table 2). Only two participants ascribed no responsibility at all. However, between the two voting rounds a significant change in opinion is observed. In the second voting round most participants ascribed none or only very little responsibility to David (see first row in Table 3). Only one participant ascribed David Jackson a high degree of responsibility for improving the test methods. In Fig. 2 this shift is graphically shown. The blue bars depict the number of votes in the first round, whereas the red bars depict the number of votes in the second round.

To get more insight in the learning effects triggered during the discussion it is interesting to distinguish between 'active discussants' and participants who did not contribute to the discussion. The latter were of course able to follow the discussion, but since these participants did not actively engage in the discussion it seems likely that the learning effects are also less pronounced. To see whether this is indeed the case let us take a look again at David Jackson's responsibility for improving the test methods, but now at a more fine-grained level. Of the eight participants four actively engaged in discussion on this particular actor-responsibility combination. If we divide the histogram in Fig. 2 in two parts, one for the participants who actively discussed this topic and one for the participants who did not, we have a preliminary indication of the effect of active engagement in the discussion. The result is shown in Figs. 3 and 4. Figure 3 shows the same data as Fig. 2 but then for the participants who engaged in discussion only, whereas Fig. 4 shows these data for the participants who did not engage in the discussion. Figure 3 shows a clear convergence between the first and second voting round, whereas this convergence less visible in Fig. 4. Hence the participants who actively engaged in the discussion did, on average, show a more radical shift and a stronger convergence compared to the participants who did not engage into the discussion. 


\section{Responsibility Ascription}

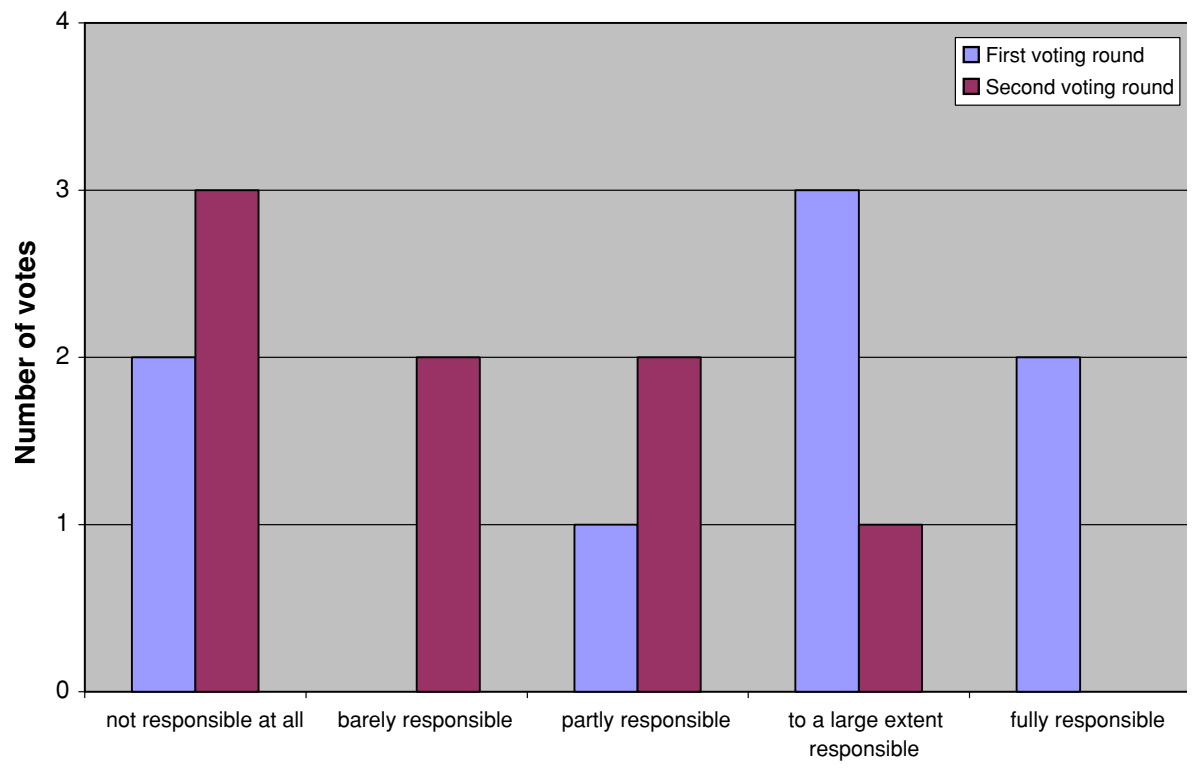

Degree of responsibility

Fig. 2 Responsibility ascription to David Jackson for improvement of the test methods

\section{Responsibility ascriptions by participants who engaged in discussion}

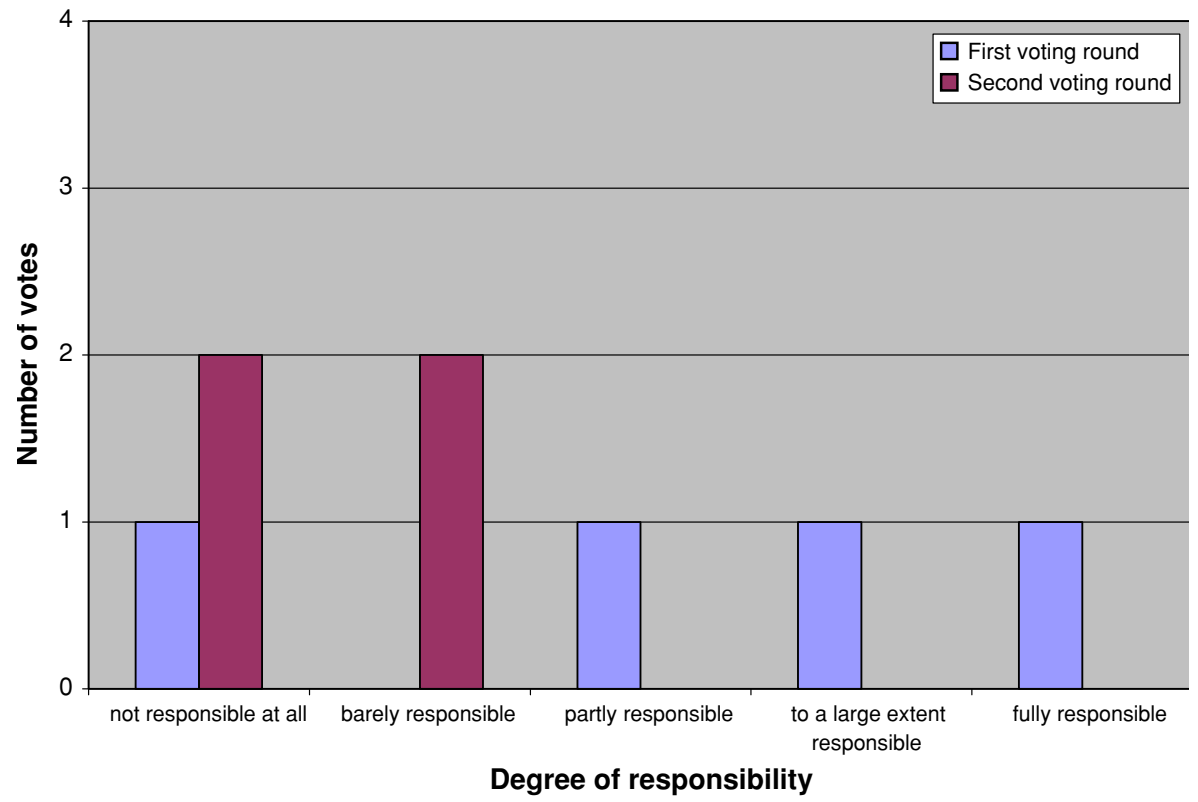

Fig. 3 Responsibility ascriptions to David Jackson for improvement of the test methods (discussants only) 


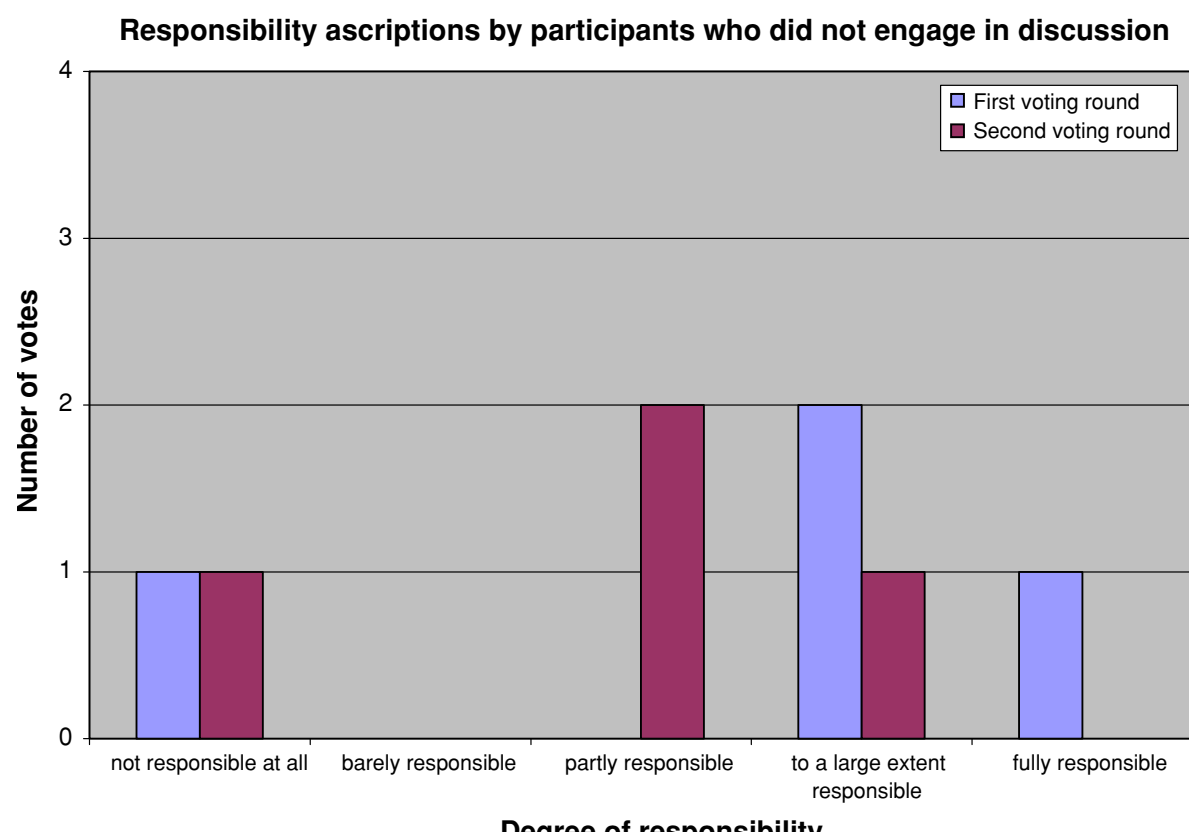

Fig. 4 Responsibility ascriptions to David Jackson for improvement of the test methods (non-discussants only)

The same procedure is followed for Diane Collins' responsibility to inform the local authorities about the flaws in the test method. All participants actively engaged in the discussion on this topic so no distinction can be made between active discussants and participants who did not engage in the discussion. The voting results for this particular combination of actor and responsibility are shown in Fig. 5. The figure shows that the participants tended to increase the degree of responsibility between the first and second voting round. It can also be seen that the participants tended to converge to a high level of responsibility for Diane Collins. One of the participants who shifted the degree of responsibility from 0 (not responsible at all) to 4 (fully responsible) explained that he increased the level of responsibility for the higher management partly due to the discussion.

A number of participants mentioned that the session did not so much trigger moral learning effects but served mainly an explanatory purpose. Shifts in opinion, one of the participants argued, were mainly due to clarification of the terms. The apparent lack of clarity in some of the responsibilities is partly due to the fact that the case was a hypothetical case which might somewhat hamper clear task divisions. Moreover, the discussions on the disagreements were done electronically and not orally. In a real case the results of the electronic discussion could serve as a base for further oral discussion. In that sense the learning effects are indeed an effect of the case selected and the system used. However, it is striking that of the eight participants, especially the ones who worked in the field of water management were most positive about the use of the session. They argued that the session was useful 
Responsibility Ascriptions

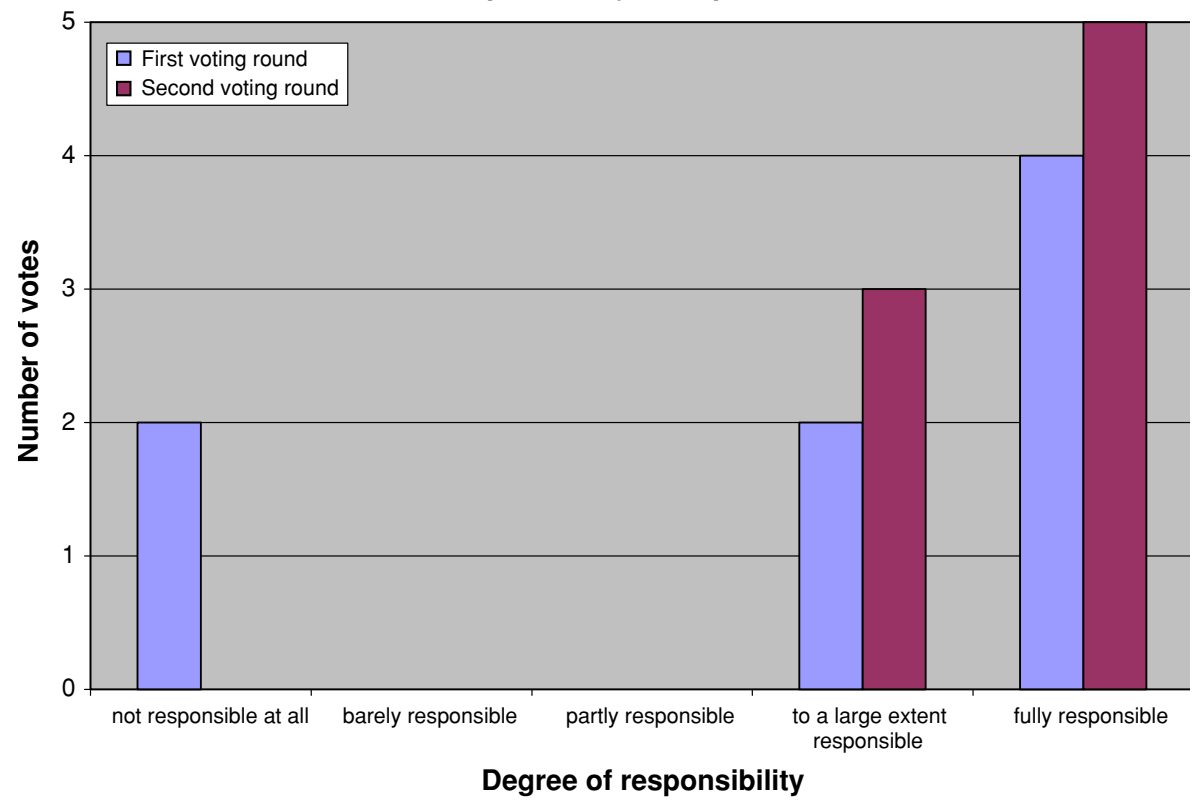

Fig. 5 Responsibility ascriptions to Diane Collins for informing local authorities about contamination in sludge

because it encouraged "to form an opinion and to look at the case from a different perspective" and it made one "think what responsibility really is and what is required to ascribe it to someone." This suggests that part of the conceptual clarification is not just an 'artifact' of the system used but part of actual learning. Lack of clarity on the exact functions and roles of different actors in a network is not only a result of the methodology followed, it is something which occurs in real life as well. One of the participants did indeed argue that the session helped to form a clearer picture of the whole chain of production and emission and that this helped him to understand the differences in opinions on responsibilities. It is likely that in a 'real case', this overview of a whole chain is often lacking as well. In that sense the conceptual clarification could be considered a genuine learning effect.

To come back to the question whether an interactive session leads to the construction of an overlapping consensus we could tentatively say that the session triggers learning effects, which are a sine qua non for genuine learning. Whether these learning effects also lead to an overlapping consensus is something that needs to be explored in further detail in a real case. The results so far seem to suggest that participation in an interactive session in general may contribute to some convergence on opinions, which holds even stronger if the participants actively engage in the discussions. However, to say that an overlapping consensus will ultimately be achieved is a much stronger claim. An overlapping consensus is only justified if it is acceptable to all relevant actors, or if at least all their considerations, including their personal objectives and agendas, are taken into account. In a 
hypothetical case it is difficult to include all these considerations. One could assess whether the participants in a session reach a consensus on certain topics but it is not possible to see whether this is a justified consensus. A consensus is only justified if it really fits within each individual's WRE. Hence, consensus as a consequence of groupthink cannot be considered a justified consensus. Moreover, most responsibility ascriptions depend, at least partly, on contextual factors, e.g. prevailing legislation, technical details. In a hypothetical case this kind of information is lacking. For some issues the participants in the session could therefore only give $a$ proviso responsibility ascriptions, pending the contextual details.

\section{Conclusions and Future Research}

In this paper, I have described the results of an interactive session in which different people's opinions on responsibility were empirically traced. The Rawlsian concept of WRE and overlapping consensus were used to analyze the results. The EPQ was used to assess the people's moral background theories. The responsibility conditions were conceived as the moral principles and the distribution of responsibilities as considered judgments.

Although a consensus was not reached, the session showed that it is possible to uncover the relevant data to assess a consensus amongst people in terms of their individual WRE. It appeared that the moral background theories people endorse are not predictive for their actual distribution of responsibilities. The background theories do, however, indicate ways of reasoning and justifying outcomes. The EPQ proved to be a useful tool for assessing these background theories. Two ways of ascribing responsibilities were distinguished, corresponding to two requirements of a desirable responsibility distribution: fairness and completeness. People who focus on the fairness criterion appeared to put more emphasis on the responsibility conditions.

With regard to the more substantive aim of the project, the session triggered learning effects. Although explanatory learning effects were dominant, moral learning was observed as well. Especially between the people who actively engaged in the discussion some convergence on opinions was observed. Whether these are sufficient for an overlapping consensus could not be established on the basis of this hypothetical case.

In the present paper the WRE approach was applied to a more or less artificially constructed network, where no real interests were at stake. The next step will be to apply the method to a real engineering case. An interactive session as described in the present paper can then be part of an embedded ethical research that is carried out parallel to the technical research (Van der Burg 2009; Zwart et al. 2006). In such a project, the role of the engineering ethicists could become one of helping to elucidate issues that are otherwise overlooked. It should be investigated whether such an approach is indeed feasible (in the sense that it is supported by the engineers and that they are willing to cooperate) and whether it leads to an overlapping consensus on a responsibility distribution which is justifiable to all and in which no responsibilities are left unfulfilled. If this is the case the present approach can be 
pursued further, especially in large projects where many different actors work together, therewith trying to contribute to the solution of the problem of many hands.

Text box Gilbane Gold case

The videotape Gilbane Gold was originally prepared by the National Institute for Engineering Ethics for the National Society of Professional Engineers as a case to be used in engineering ethics education. Although the case primarily addresses the issue of whistle blowing, the case could also be considered exemplifying problems in the distribution responsibilities.

The case takes place in the imaginary town of Gilbane. The dried sludge from the city's wastewater treatment plant has been used for over 75 years as a fertilizer. It is sold to local farmers under the name of Gilbane Gold. Since the area of Gilbane accommodates several hightech firms, strict regulations were enacted on the discharge of heavy metals (arsenic and lead) several years ago. These restrictions are ten times more stringent than federal regulations. The limits are based on the concentration of the pollutants in the discharge with no restrictions on the total quantity of contaminated material discharged. The firms are responsible for supplying the city with discharge data based on a prescribed test method. These data must be signed off for accuracy by an environmental engineer.

David Jackson is a junior environmental engineer working for Gilbane's chip manufacturer ZCorp. David is concerned about the company's discharge since a newer, and more sensitive, test reveals that the firm has occasionally been slightly exceeding the allowable emissions. However, this newer test is not prescribed by the city. David Jackson proposes to talk to the city about the new test but the firm's management is against disclosing the test results. By disclosing the results to the city the company would risk legal action and maybe even stricter regulation.

Some time later the company signs a contract which implies a five times higher production level and accordingly, a five times higher discharge of arsenic and lead. Although the firm is strictly speaking still within city regulations - after all, these were phrased in terms of concentration and not in terms of total quantity-David decides to blow the whistle and inform a local TV newscaster on the plant's discharge levels.

In addition to David Jackson, several other characters play a role in the movie: Phil Port, manager in charge of environmental affairs under whom David works; Frank Seeders, Engineering Manager; Tom Richards, environmental engineering consultant fired by Z-Corp; Winslow Massin, retired professor of engineering; Diane Collins, vice-president of the local Z-Corp plant; Maria Renato, TV reporter from Channel 13; and Lloyd Bremen, former state commissioner of environmental protection.

Acknowledgements This research is part of the research program Moral Responsibility in R\&D Networks, which is supported by the Netherlands Organisation for Scientific Research (NWO) under grant number 360-20-160. The participants of the GDR session are gratefully acknowledged for their helpful cooperation. I would also like to thank Ibo van de Poel and the anonymous referees for the valuable comments they provided on an earlier draft of this article.

Open Access This article is distributed under the terms of the Creative Commons Attribution Noncommercial License which permits any noncommercial use, distribution, and reproduction in any medium, provided the original author(s) and source are credited.

\section{Appendix: Discussion of the Participant's Reflective Equilibriums}

In this appendix the reflective equilibrium of each individual participant is discussed. Since the moral background of the individual participants were not considered as being open for revision these equilibriums should be considered 
narrow. Only if the moral background theories would have been included in the reflective process, the equilibrium could have been regarded as wide reflective equilibrium.

The first participant is participant $\mathrm{Z},{ }^{10}$ who scored relatively high on the universalism dimension (5.4) ${ }^{11}$ and low on the idealism dimension (3.3) and who could hence be considered an 'exceptionist'. Exceptionists have a pragmatic stance. They think that one is morally bound to act in a way that produces good consequences. $\mathrm{Z}$ argued for 'legal' or more business-like models to distribute responsibilities because these lead to "a system where local optimization (of the employee in his position) has the desired effect of optimalization of the whole company. This distribution does not necessarily have to fit from a moral point of view." Without discussing into detail Z's reasoning, it has an unmistakably pragmatic character, which is in accordance with Z's ethical position. In the discussion $\mathrm{Z}$ rejected responsibility for the environmental activist group "because it is difficult to ascribe responsibility for groups of volunteers." The same participant rejected Tom Richard's responsibility to carry out R\&D for Z-corp "because he has reasons to assume that they will not listen to him." In terms of the responsibility conditions participant $\mathrm{Z}$ argued that one of the prerequisites to ascribe responsibility is that the person has the right, power and possibility for action. Hence, there is a strong coherence between this participant's background theories, moral principles and considered judgments. As such we could prudently argue that this participant has attained a reflective equilibrium.

A second example is participant Y. Y scored relatively high on both idealism (6) and universalism (5.9), which positions him as an 'absolutist'. According to Forsyth's classification absolutists assume that the best possible outcome can always be achieved by following moral rules. In the discussion on the responsibility conditions $\mathrm{Y}$ argued for occupational safeguards for whistle-blowers, which suggests that whistle-blowing is sometimes unavoidable in the first place. This was later confirmed in the discussion on David Jackson's role in 'good housekeeping in industrial processes', where Y mentioned whistle-blowing as the ultimate responsibility of David Jackson if his superiors would not take adequate measures. The latter is a rather deontological position. For people who adhere to ethical skepticism, for example, whistle-blowing is probably less often the preferred solution.

In the comments $\mathrm{Y}$ made a difference between responsibility stemming from formal tasks and a broader societal responsibility stemming from moral commitment. $\mathrm{Y}$ argued that on the former kind of responsibility people will most likely agree, whereas the latter is "more closely linked to a view on society where the first consideration is cooperation as such to solve socio-technical problems." In the discussion on the different actor-responsibility combinations Y made this distinction between formal and broader responsibility a number of times. With regard to the

\footnotetext{
10 To anonimize the results all participants are indicated with a letter and a male possessive pronoun.

11 The score on the universalism dimension can be obtained by subtracting the score on the relativism dimension from 10 .
} 
environmental activists group's responsibility to inform farmers $Y$ argued that "in a formal sense, the task of environmental activists groups is to support the interests of their members, and to inform and influence governments. However, if it contributes to the efficacy of their action to inform the farmers, I see no reason why this is not their responsibility." A similar argument was given in the discussion on the question whether David Jackson is responsible for the determination of the toxicity of the sludge where Y remarked that "in a narrow, formal sense, there is no responsibility for the environmental engineer. But since an observing person in his function will be curious about the results of the companies' actions, he should at least know about the results and report these to the higher management."

Y's 'broad' conception of responsibility coheres with a high score on the idealism dimension. Since idealism refers to the extent to which a person believes that the right course of action always yields desirable outcomes, idealists are probably less prone to make moral compromises. People with a low score on the idealism dimension admit that the 'right' action yields some tolerable mix of desirable and undesirable outcomes (Forsyth 1980, p. 176). The reference to broader societal responsibilities reflects a vision where people transcend the level of (formal) task assignment and exhibit a (pro-active) attitude to make true the ideal world. As such Y's background theories and considered judgments seem to be in equilibrium. With regard to the moral principles the equilibrium is less clear. It is somewhat surprising that $\mathrm{Y}$ included the condition "no unfavorable consequences for oneself' as a necessary condition for ascribing responsibility. The other opinions of $\mathrm{Y}$ point at a more strict position, on the basis of which one would have expected the occurrence or otherwise of unfavorable consequences to be less relevant. However, in the discussion on this particular condition $\mathrm{Y}$ argued for protective occupational measures, which seems to suggest that $\mathrm{Y}$ does not as much consider the absence of unfavorable consequences to be a necessary condition for ascribing responsibility but rather the presence of these protective measures a prerequisite in occupational settings. The latter points to a broad conception of responsibility for the employer, which is in coherence with the previous considerations. The four conditions that were ranked by $\mathrm{Y}$ as the most important are the four conditions that cohere with the traditional philosophical conditions. Compared to the additional conditions which came out of the brainstorm session and which somehow seem to focus on the particularity of responsibility ascriptions, the four traditional notions are rather general or universal. Accordingly, Y's way of prioritizing the responsibility conditions seems to be in coherence with his high position on the universalism dimension. All in all Y's background theories, moral principles and considered judgments show a reasonable equilibrium.

Let us look, as a third example, to participant $\mathrm{X}$, whose score of 5.8 on the idealism dimension and 2.0 on the universalism dimension, positions him as a typical 'situationist'. According to Forsyth, situationists tend to distrust absolute moral principles and argue instead that each situation must be examined individually. They focus on contextual appropriateness, not the 'good' or the 'right' but the 'fitting'. Each situation must be examined individually (Forsyth 1980, p. 176). For X, the responsibility with the highest ranking is 'commitment'. The second most important 
condition is 'opportunity for action'. Both conditions emphasize the contextual embeddedness of action. Especially the high ranking of the 'commitment' condition is striking. For $\mathrm{X}$ this was the most important condition for holding someone responsible. In the discussion of David Jackson's responsibility for good housekeeping in the industrial process $X$ argued that "if he does not get support by higher management, $[\ldots]$ not much will happen. His subordinates will point at his superiors and show no enthusiasm whatsoever [to improve the industrial processes]." Compared to the other participants, $\mathrm{X}$ also placed the 'competency' condition rather high in the ranking of the conditions. In the discussion this emphasis on competency was reflected in comments like "the development of tests/analytical methods is a very specialized business for specialized bureaus/institutions" and "the development and improvement of testing methods is not a responsibility of the company but for some 'Bureau of Standards', possibly delegated to specialized industry."

In the attribution of responsibilities participant $\mathrm{X}$ was rather distinct. None of the actors was given a level of 'barely responsible' and only few a level of 'partly responsible' or 'to a large extent responsible'. Compared to the other participants X ascribed relatively often a level of 'fully responsible'. With the emphasis on especially the contextuality of responsibility and, to a lesser degree, the requirement of competency, X's background theories, moral principles and considered judgments show a remarkable strong coherence.

Another typical situationist is participant W (score of 6.3 on the idealism dimension and 3.4 on the universalism dimension). Similar to $\mathrm{X}, \mathrm{W}$ gave the 'commitment' condition a relatively high ranking. It is therefore not surprising to see similar arguments about, for example, David Jackson's subordinate position within Z-corp. Both argued that he cannot be held responsible for the overall process because "he is just an engineer". However, contrary to X, W added that David, being an environmental engineer, "should feel responsible for good environmental management." This broad conception of responsibility, with a focus on responsible behavior and not merely task assignment, is similar to what we saw in the discussion of Y's considerations. In the discussion of the responsibility of the press, W argued that although it is not the media's responsibility to inform the farmers, they should announce the news if the farmers know that Gilbane Gold is polluted and they deliberately remain silent. A similar argument was given on Diane Collin's responsibility to improve the test methods, where W argued that although Diane Collins is not responsible for "improvement of the test methods in the sense of development of new ideas", as the vice-president she has "the responsibility to put some budget in this direction."

A striking thing in W's discussion on the improvement of the test methods is the remark that the whole discussion "misses the point. There are test methods and they show contamination; improving test methods seems to distract the attention from this issue." With this implicit call for active measures rather than looking for responsibility conditions $\mathrm{W}$ seems to emphasize the completeness requirement of the responsibility distribution more than the fairness requirement. The issue of fairness did come up, however, in the justification afterwards. W addressed the issue of fairness when he explained that "in the discussion I felt confirmed in employee's innocence, but with some moral responsibility nevertheless. [...] I saw some 
emphasizing the responsibility of the management. I think this made me assign a bit more responsibility to them in the second round."

Summarizing, in the discussions and in the different voting rounds both the relativistic tendency and the idealistic tendency were clearly visible. In the moral principles high priority was given to the 'commitment' condition. Taken together, participant W's background theories, moral principles and considered judgments are mutually consistent. As such we can conclude that $\mathrm{W}$ has attained reflective equilibrium.

With a score of 4.9 on the idealism dimension and 5.8 on the universalism dimension participant S's ethical position is a mixture of absolutism and exceptionism. S argued that "Z-corp should inform the authorities if they cannot guarantee the quality of the water", which points at a rather 'duty-oriented' position. In the justification afterwards participant $\mathrm{S}$ mentioned that "through the discussion I became more distinct in the assignment of responsibilities: not everyone a little bit but appointing clear parties." However, an analysis of the voting results of S showed that the voting results between the first and second voting round became not as much more distinct, but were on average significantly higher. The number of actor-responsibility combinations for which $\mathrm{S}$ assigned a responsibility level equal to 0 (i.e., "not responsible at all") or 1 (i.e., "barely responsible") reduced from 41 to 33. The number of actor-responsibility combinations with a level of responsibility equal to 2 (i.e., "partly responsible") increased from 2 to 9. The number of actorresponsibility combinations with a level of responsibility equal to 3 (i.e., "to a large extent responsible") or 4 (i.e., "fully responsible") increased from 13 to 14. This means that the shift in the voting results was mainly from a very low level of responsibility to a moderate level of responsibility.

A recurrent issue in S's contributions to the discussions is the responsibility to offer certain quality. In the discussion on whose task it is to inform the authorities on the contamination, $S$ argued that "Z-corp should inform the authorities if they cannot guarantee the quality of the outflow water." In the discussion on the responsibility of the customers of Gilbane Gold (i.e., the agricultural sector) $\mathrm{Z}$ mentioned that "their role has somewhat disappeared in the discussion. They do have a product responsibility though and they should not take everything for granted that has been offered to them." This seems to point to a notion of responsibility as a 'professional duty'. In the ranking of the responsibility conditions this professional viewpoint is exemplified in the high priority given to the conditions 'competency', 'knowledge' and 'task'. In S' view these conditions seem to point to a duty: if one has certain knowledge, a certain competency or is assigned a certain task, one has the duty or obligation to take up one's responsibility.

Although S does not have a very distinct position on the EPQ scales, there seems to be a slight favor of idealism (as opposed to subjectivism), which means that $S$ tends to "assume that desirable consequences can, with the 'right' action, always be obtained" and a somewhat stronger appraisal of universalism (as opposed to situanionism), which means that $S$ "tends to rely on universal moral rules" (Forsyth 1980 , p. 175). This deontological tendency is in line with the conception of responsibility as a duty. Hence, the background theories, moral principles and considered judgments show a rather good coherence. 
Participant $\mathrm{T}$ has a relatively high score on the idealism dimension (6.2) and an average score on the universalism dimension (4.9), which positions $\mathrm{T}$ somewhere between the positions of absolutism and situationism. Participant $\mathrm{T}$ referred to the notion of task several times. In the discussions on the testing of the contamination in the outflow of the Z-corp factory, for example, $\mathrm{T}$ argued that "if it is about methods for measuring poisonous material in the waste water of the company, it is of course the responsibility of the company itself, and so, at the highest level, of the manager". In the justification afterwards $\mathrm{T}$ mentioned that "discussion and exchange of arguments did not so much change your opinion on who is responsible for what but it mainly served to get a clear picture of the exact definition of tasks and functions of the different actors involved. Distribution of responsibilities is dependent on these." Considering this focus on tasks, it is somewhat surprising that $\mathrm{T}$ did not give a high priority to 'task' as a condition. The condition task was included as a necessary condition, but it was low in the ranking.

The reasoning of participant $\mathrm{V}$, with a score of 6.7 on the idealism dimension and 4.1 on the universalism dimension a typical situationist, shows a striking similarity to that of participant T. Similar to T, V emphasized the role or task of actors. In the ranking the 'task' condition is therefore also relatively high. However, for both $\mathrm{T}$ and $\mathrm{V}$ this focus on task was combined with a particular idealistic view on responsibility. The question 'who is responsible?' was coupled to the question 'what is the moral consequence of not carrying out that responsibility?'. For example, V emphasized the responsibility of Z-corp to carry out measurements within the factory since "concentrations should be measured where they are emitted." The reason why it is the company, and not the local authorities to carry out these measurements, is that "if they would do so, it would give the management of the firm an excuse not to accurately carry out the measurements and to deny the problem as long as there is not an improved method available." This suggests that the denial of the problem by the company is a bad thing per se, and not so much because of potential damage. After all, if the local authorities would have been ascribed the responsibility to carry out the measurements and if they would carry out this task satisfactorily, the denial of the problem by Z-corp would, for consequentialist reasons, not be much of problem. After all, the local authorities will do the testing and carry out adequate measures. Hence, for $\mathrm{V}$ denial of the problem by Zcorp seems to be problematic for moral reasons. In the discussion on the role of the environmental activists group $\mathrm{T}$ expressed a similar idealistic view. $\mathrm{T}$ argued that "it is maybe not their responsibility [to inform the farmers] in the sense that there will be repercussions for them if they don't do it, but it is something that is expected of them." With regard to Tom Richards' role T argued that "he is responsible to point out to others (the factory and if necessary the authorities) that the current methods are not adequate", which is rather demanding compared to the opinions of other participants. Both $\mathrm{T}$ and $\mathrm{V}$ seemed to be less prone to make moral compromises, which is in accordance with the high score on idealism.

Summarizing, the contribution to the discussions and the voting results of participant $\mathrm{T}$ and $\mathrm{V}$ are rather consistent with the high score on the idealism dimension. Although T emphasized the importance of task assignment, professional roles or tasks do not give an excuse for not taking up a responsibility in T's 
considerations. It is rather the other way around; both $\mathrm{T}$ and $\mathrm{V}$ approached the question of responsibility from a duty-like perspective: given a certain role or task, what is morally expected? Compared to participant $\mathrm{T}$, participant $\mathrm{V}$ has a lower score on the universalism dimension, which becomes apparent in the contextual factors that are taken into account. In the discussion on Diane Collins' responsibilities V assigned responsibility "only as far as she can know and estimate". The environmental activists group's responsibility to inform other is directed towards the party "that has itself a responsibility and that has the power to change things." On the basis of the above, both T's and V's considerations show a rather good coherence. They use similar arguments for distributing responsibilities. The differences between them can be explained in terms of the diverging score on the universalism dimension. Accordingly, we can conclude that they both have attained a high degree of equilibrium.

Participant U, whose score of 6.1 on the idealism dimension and 3.6 on the universalism dimension indicates a tendency towards situationism, also emphasized the contextuality of responsibility. In order to be responsible one should have insight in the boundary conditions and possible other related responsibilities, $\mathrm{U}$ argued during the discussion on responsibility conditions. These 'other' responsibilities frequently appeared in the discussion of the different actor-responsibility combinations. In the discussion on Diane Collins' responsibility for improvement of the test methods, for example, $\mathrm{U}$ argued that Diane Collins "is only responsible if she thinks that the current test methods undermine the company's position", with this pointing at Diane Collins' responsibility as manager of a firm. Another example of 'contextuality' was found in U's discussion about the local water authority's responsibility for the improvement of the test methods. The local water authority, $U$ argued, is "only responsible to the extent that local circumstances should be taken into account."

It seems that U's opinion on responsibility is rather 'task-driven': Tom Richards, for example, has no responsibility to carry out R\&D for Z-corp, "other than by explicit commission." Phil Port has no responsibility for improving test methods; he is "only responsible for compliance." These examples show that U seemed to aim at a rather clear task division, not one defined in terms of broader societal responsibilities. In his justification/explanation afterwards participant $\mathrm{U}$ mentioned that the discussion mainly served an explanatory purpose and that it helped to form "a workable definition of responsibility" (though he attributed this to the discussion itself, not to the system used). Task was indeed one of the necessary conditions for responsibility, in U's ranking. In the discussion U seemed to emphasize the fairness condition more than the completeness conditions. In stead of approaching the different responsibilities from a perspective of 'who should do this particular task', $\mathrm{U}$ seemed to approach it from the actor side 'is it reasonable/fair to ascribe this particular responsibility to this particular actor'. The former seems to point at completeness, whereas the latter seems to point at fairness.

U's low position on the universalism dimension, the ranking of the responsibility conditions and the contribution to the discussions, show a rather high consistency. Apparently, $\mathrm{U}$ has attained a significant degree of equilibrium. 


\section{References}

Achrol, R. S. (1997). Changes in the theory of interorganizational relations in marketing: Towards a network paradigm. Journal of the Academy of Marketing Science, 25, 56-71.

Bovens, M. (1998). The quest for responsibility. Accountability and citizenship in complex organisations. Cambridge: Cambridge University Press.

Callon, M., Laredo, P., Rabeharisoa, V., Gonard, T., \& Leray, T. (1992). The management and evaluation of technological programs and the dynamics of techno-economic networks: The case of the AFME. Research Policy, 21, 215-236.

Corlett, J. A. (2001). Collective moral responsibility. Journal of Social Philosophy, 32, 573-584.

Dancy, J. (2004). Ethics without principles. Oxford: Oxford University Press.

Daniels, N. (1979). Wide reflective equilibrium and theory acceptance in ethics. Journal of Philosophy, 76, 256-282.

Daniels, N. (1996). Justice and justification. Reflective equilibrium in theory and practice. Cambridge: Cambridge University Press.

Feinberg, J. (1970). Doing and deserving. Essays in the theory of responsibility. Princeton: Princeton University Press.

Fischer, J. M., \& Ravizza, M. (Eds.). (1993). Perspectives on moral responsibility. Ithaca: Cornell University Press.

Forsyth, D. R. (1980). A taxonomy of ethical ideologies. Journal of Personality and Social Psychology, 39, 175-184.

Forsyth, D. R., \& Berger, R. E. (1982). The effects of ethical ideology on moral behavior. Journal of Social Psychology, 117, 53-56.

Forsyth, D. R., Bye, J. L., \& Kelley, K. N. (1988). Idealism, relativism, and the ethic of caring. Journal of Psychology, 122, 243-248.

Goodin, R. E. (1995). Utilitarianism as a public philosophy. Cambridge: Cambridge University Press.

Hakansson, H. (Ed.). (1989). Industrial technological development. A network approach. London: Routledge.

Halal, W. (1994). The formation of inter-organizational networks. Academy of Management Executive, 8, 69-83.

Hooker, B., \& Little, M. (Eds.). (2000). Moral particularism. Oxford: Oxford University Press.

Kohlberg, L. (1976). Moralization: The cognitive-developmental approach. In T. Likona (Ed.), Morality: Theory, research and social issues. New York: Holt, Rinehart and Winston.

May, L., \& Hoffman, S. (1991). Collective responsibility. Five decades of debate in theoretical and applied ethics. Savage, MD: Rowman \& Littlefield Publishers.

Musschenga, A. W. (2005). Empirical ethics, context-sensitivity, and contextualism. Journal of Medicine and Philosophy, 30, 467-490.

Nihlén Fahlquist, J. (2006). Responsibility ascriptions and vision zero. Accident Analysis and Prevention, 38, 1113-1118.

Rawls, J. (1999 [1971]). A theory of justice. Cambridge (Ma.): The Belknap Press of Harvard University Press.

Rogers, J. D., \& Bozeman, B. (2001). "Knowledge value alliances": An alternative to the R\&D project focus in evaluation. Science, Technology \& Human Values, 26, 23-55.

Saari, E., \& Miettinen, R. (2001). Dynamics of change in research work: Constructing a new research area in a research group. Science, Technology \& Human Values, 26, 300-321.

Swierstra, T., \& Jelsma, J. (2006). Responsibility without moralism in techno-scientific design practice. Science, Technology \& Human Values, 31, 309-332.

Thompson, D. F. (1980). Moral responsibility and public officials. American Political Science Review, 74, 905-916.

Van de Poel, I., \& Zwart, S. D. (2009). Reflective Equilibrium in R\&D Networks. Science, Technology \& Human Values. doi:10.1177/0162243909340272.

Van der Burg, S. (2009). Imagining the future of photoacoustic mammography. Science and Engineering Ethics, 15, 97-110.

Zwart, S. D., Van de Poel, I., Van Mil, H., \& Brumsen, M. (2006). A network approach for distinguishing ethical issues in research and development. Science and Engineering Ethics, 12, 663-684. 